\title{
House Prices \& Property Tax Revenues During the Boom \& Bust: Evidence from Small-Area Estimates*
}

\author{
Christopher B. Goodman ${ }^{\dagger} \quad$ University of Nebraska at Omaha
}

\begin{abstract}
Although the Great Recession put the U.S. economy into a tailspin, we know little about how the changes in house prices influenced property tax collections. Using local level housing data from Zillow $^{\circledR}$ matched to property tax data from 1998 to 2012, two questions are examined. First, the elasticity of property tax revenue with respect to house values is estimated. Second, the timing of this elasticity is determined. The analysis rules out that local policymakers capture the entire increase of house value in property tax revenues but unable to rule out that increases in house values are completely offset by changes in effective property tax rates. Decreases in values have an elasticity between 0.3 and 0.4 and take three years for changes in values to impact property tax revenues. While property tax collections declined, local policymakers adjusted effective millage rates such that revenues did not decline as much as home values.
\end{abstract}

Keywords: Property tax, house prices, distributed lag model, tax base elasticity

\section{Introduction}

Both historically and contemporaneously, the property tax is an important source of revenue for local governments in the United States. However, through the recent financial crisis, the once stable property tax has been tested by rapidly appreciating and then declining house prices. Recent research has brought to light the connection between changes in house prices and changes in property tax revenue at the national as well as the local level (Lutz 2008). This research suggests that house price appreciation is not 100 percent incorporated into property tax revenues because of reductions in effective tax rates. Additionally, it takes three years for house price appreciation to impact property tax revenues. Further research has tested this proposition and suggests that while house prices matter, they do not matter to the degree one might expect (Doerner and Ihlanfeldt 2011).

Due to data limitations in some previous studies, the estimates of the relationship between house prices and property tax revenues rely on house price data aggregated to a scale larger than the unit of observation. As such, variations in local property tax revenue are being explained by trends in state or metropolitan level variation in house prices. This approach ignores intra-state or intra-MSA variation of house prices that may explain significantly more of the variation in changes to property tax revenue. Additionally, few studies have expressly examined the influence of the housing price crash associated with the Great Recession. This paper proposes to fill this void by replicating the econometric analysis of Lutz (2008) to further explore the relationship utilizing more recent data covering the housing crisis. Using annual data on median house values supplied

*Forthcoming at Growth \& Change.

${ }^{\dagger}$ September 11, 2018 
by Zillow ${ }^{\circledR}$ at the city and county level and combining these data with annual property tax revenue data from the U.S. Census Bureau, more accurate small area estimates of the influence of house value changes on property tax revenue changes can be ascertained. Given that home prices are currently rising in many cities, better understanding this relationship has important implications for the ongoing fiscal affairs of local governments.

This paper proceeds as follows. First, an examination of the recent literature pertaining to the influence of house prices on local government finances is conducted. Second, an overview of the influence of rising house prices on property tax revenues is conducted and two testable questions are examined. Third, the house price data utilized for this analysis is examined and compared to other house price indices. The econometric model is introduced, and a series of results are examined. Finally, policy implications are discussed.

\section{Previous Literature}

The previous literature on the influence of house price changes on local government finances is sparse. However, there is a small yet growing literature examining the numerous facets of this relationship. Lutz (2008) presents one of the first examinations of the influence of rising and falling house prices on property tax revenues at both a national and a local scale. Using the OFHEO/FHFA house price index and data from Census Bureau's state and local government finance data, Lutz concludes that the elasticity of property tax revenue with respect to house prices is approximately 0.4 and it takes three years for these changes in house prices to be incorporated into revenues. This result implies that local policy makers offset approximately 60 percent of the potential increase in property tax revenues as a result of rising house prices by reducing effective tax rates. Declines in house prices are associated with an increase in property tax revenue suggesting local policy makers adjust effective tax rates upward to keep property tax revenues relatively constant. Important to this analysis, Lutz (2008) suggests that the results regarding declining house prices are unreliable because his sample contains few examples of declines in house prices. This analysis is an extension of Lutz's contribution and his estimation technique will be discussed at length below.

Lutz, Molloy, and Shan (2011) follows up on Lutz (2008) by examining a number of pathways by which changes in house prices can be incorporated into state and local revenues. Of interest for this analysis is their first analysis reexamining the findings of Lutz (2008) and focusing specifically on decreases in house prices. Ultimately, they conclude that property tax revenues tend not to decline in the face of declining house prices. This is the result of lags in the process of translating declines in house prices into assessed values and the actions of local policy makers offsetting declines with effective tax rate increases. Similar to Lutz (2008), Lutz, Molloy, and Shan (2011) suggest that there are too few instances of house price declines and the declines are of such a small size that identifying the influence of negative changes in house prices on property tax revenues is difficult. This is largely the result of inadequate data (both housing and local government revenue) covering the recent housing crisis.

In an examination of California cities, Vlaicu and Whalley (2011) find that there is a strong relationship between house price appreciation and property tax revenues. As Ihlanfeldt (2011) notes, this particular finding is surprising because of the restrictions placed on both tax rates and assessed values as a result of Proposition 13. They find an elasticity of property tax revenue with respect to house prices of 0.74 and are unable to distinguish this result from one. This result 
is quite large and stands in stark contrast to the findings of Lutz (2008) and Lutz, Molloy, and Shan (2011). Additionally, Vlaicu and Whalley (2011) find that increases in house prices leads to a reduction in other local tax revenue (an elasticity of -0.55), but no influence on total city expenditures. This finding suggests that increases in property tax revenue as a result of house price changes are completely offset by reductions in other local tax revenues, thus holding overall expenditure constant.

Examining cities in Florida, Doerner and Ihlanfeldt (2011) find that house prices influence a number of revenues sources, but the connection between house prices and assessed values and house prices and property tax revenues are small. Unlike Vlaicu and Whalley (2011), Doerner and Ihlanfeldt find that house price appreciation does increase city revenues. However, the relationship is complex and they suggest "it is wrong to conclude that changes in house price, by altering ad valorem tax revenues, drive local budgets up or down" (pg. 341). Exploring this complexity, Ihlanfeldt (2011) finds that increases in the property tax base result in little change in property tax revenue because of near complete offset of millage rates in Florida counties. Florida cities do not engage in complete millage rate offsets, rather, they tend to alter expenditures to balance their budget. Alm, Buschman, and Sjoquist (2011) find a relationship between house prices and property tax revenues; however, there is significant variability by state and locality. This variability kept a large number of local governments from experiencing the kind of fiscal decline experienced at the federal and state level. In an analysis of school districts in Georgia, Alm, Buschman, and Sjoquist (2011) demonstrate that rising assessed values tend to be associated with increases in district spending and Georgia school districts tend to engage in some limited offset of effective property tax rates as a result of rising assessed values. These results are supportive of the findings of Lutz (2008). Finally, Mikesell and Liu (2013) find a positive relationship between house prices and assessed value in a sample of large cities in U.S. with a fairly stable elasticity of 0.4 . The subsequent influence of lagged assessed value on property tax revenue is negative and nearly one suggesting a complete offset to increases in assessed value. This result is consistent with Ihlanfeldt (2011).

What is clear from the limited literature on the influence of house prices on local government finances is data from the most recent crisis has largely been unavailable to researchers. All the analyses cited above end their time series before the bottom of the housing crash (See Figure 2). Depending on the index, national house prices bottomed out at some point in 2011. The latest end point for these analyses is 2011 (Mikesell and Liu 2013) and many end prior to this date. ${ }^{1}$ This has led to problems assessing the results of the recent housing crisis because the U.S. housing market has not experienced a decline of such magnitude. This analysis seeks to fill this gap with recently released data allowing estimation up to 2012.

\section{Property Tax Responses to Rising House Prices}

The real property tax is assessed on the aggregate value of land and improvements minus any exemptions from the tax base. The land and improvements included in the property tax base are composed of a number of different types of property. Single and multifamily housing accounts for approximately 61 percent of the total property tax base (U.S. Census Bureau 1987). ${ }^{2}$ Open acreage

\footnotetext{
${ }^{1}$ The time series end in 2005 (small area estimates) or 2007 (national estimates) inLutz (2008); 2007 for Lutz, Molloy, and Shan (2011) and Vlaicu and Whalley (2011); and 2008 for Doerner and Ihlanfeldt (2011).

${ }^{2}$ Unfortunately, more recent national level property tax base data is unavailable. The U.S. Census Bureau discontinued the Taxable Property Values Survey after the 1992 survey and a breakdown of usages was not included in the final
} 
and vacant yet platted lots accounts for another 12 percent of the property tax base. Commercial, industrial and other uses account for approximately 27 percent of the base. What is clear is that the residential component of the property tax base dominates. This trend continues (Gravelle and Wallace 2009) and in some ways has increased due to increased use of exemptions for a variety of purposes (Brunori 2007).

Since the property tax is administered by a hybrid of state and local actors, it displays an incredible level of diversity in the administration of the tax. However, the property tax can be defined in general as the following.

$$
R=\tau * V
$$

Where $R$ is property tax revenue, $\tau$ is the effective millage rate and $V$ is aggregate housing value. ${ }^{3}$ Equation 1 reveals the ad valorem nature of the property tax; a tax rate is applied to a fixed base. With no intervention from local policymakers, an increase in aggregate housing value necessarily leads to an increase in property tax revenue. However, this relationship is not required since policymakers can make adjustments to the effective property tax rate, blunting some or all of the impact of rising housing values. This is shown in equation 2.

$$
\Delta R=\underbrace{\tau * \Delta V}_{\text {mechanical }}+\underbrace{\Delta \tau * V}_{\text {policy offset }}
$$

A change in property tax revenue $(\Delta R)$ is a composed of two parts described by Lutz (2008) and Lutz, Molloy, and Shan (2011) as a mechanical process and a policy offset. ${ }^{4}$ In the mechanical process and assuming no policy offset, the effective property tax rate $(\tau)$ remains constant and the value of aggregate housing increases or decreases $(\Delta V)$. The result of this process is either an increase or a decrease in property tax revenue exactly equal to the change in aggregate housing value. However, local policymakers do not have to accept this mechanical process and can chose to offset some or all of the change in aggregate housing values through adjusting effective tax rates. The policy offset is the operationalization of residual view of the property tax. Complete support for the residual view would suggest that $\Delta V=-\Delta \tau$. The total effect on the change in property tax revenues is a combination of these two effects, mechanical and policy offset.

As Lutz (2008) describes, equation 2 allows the answering of two primary questions. The first assesses the elasticity of property tax revenue with respect to housing values. This essentially measures the average value of the policy offset whereby an elasticity of one indicates no offset and an elasticity of zero indicating complete offset. Elasticities between zero and one indicate a partial policy offset. It is expected that the influence of an increase in house values be treated somewhat differently by local policy makers than a decline in property values. Depending on the rapidity of increases, local policy makers may choose to capture less than 100 percent of the increase to appease local voters. Also, given that the time period of this analysis covers a significant portion of the housing crash, we might expect local policy makers to react differently to

survey. Examination of the Significant Features of the Property Tax dataset from the Lincoln Institute of Land Policy, which houses data available on property tax base characteristics, suggests this overall distribution remains but with some variation depending on the exact tax base definition utilized (Lincoln Institute of Land Policy 2015).

${ }^{3}$ This is a simplification of the property tax base. However, given the dominance of the property tax base by housing and the interest of this paper on the impact of housing on property tax revenues, it is a reasonable simplification.

${ }^{4}$ It is important to note the model proposed by Lutz (2008) and Lutz, Molloy, and Shan (2011) is not the only model of the influence of house prices on property tax revenues. (Mikesell and Liu 2013) propose and test an additional model linking all of the various stages of the property tax system. 
house price declines. Since many other local tax revenues and state aid declined during this period (Chernick, Langley, and Reschovsky 2011), local policy makers may react by holding steady or even increasing effective tax rates to blunt the impact of declining revenues elsewhere.

The second is a timing question assessing when changes in house values result in change in property tax revenues. Lutz (2008) explains this is motivated by four artifacts of the property tax. First, the administration of the property tax is backward looking. The tax is levied in the current year using assessed values from the previous year. Assuming annual assessment cycles (a particularly high bar), the earliest changes in house prices could be incorporated into property tax revenues is one year later. Second, assessment of property for tax purposes occurs at uneven intervals. For example, Ladd (1991) explains that counties in North Carolina are required to revalue property every eight years with 12 counties requiring annual assessments. This heterogeneity, even within states, suggests that the incorporation of housing values into assessed values can occur at different times. Third, most states have some form of tax and expenditure limitation (Mullins and Wallin 2004). Depending on the type of limitation, the connection between house price appreciation, assessed values, and property tax revenues will be something other than relationship outlined in equation 1. Possibly the most famous example of a tax and expenditure limit, California's Proposition 13, demonstrates this example. In 1978, Proposition 13 set current assessed values to their 1975 value, established a maximum property tax rate of one percent of assessed value and capped assessment growth to two percent per year (O'Sullivan 2001). In times when house prices appreciated faster than two percent per year, a gap between assessed value and market value forms limiting the influence of house price appreciation on property tax revenues. Additionally, property tax rates are essentially fixed allowing for little to no policy adjustment on the part of local policy makers. Finally, the property tax is often poorly administered leading to significant and intentional delays in incorporating changes in house prices into assessed values (Strumpf 1999).

\section{House Price Data Comparison}

The house price data for this analysis is derived from a rather new source, Zillow ${ }^{\circledR}$. Given the uniqueness of this dataset, both in breadth of coverage and in estimation of house prices, it warrants some explanation. Rather than being based on repeat sales data, Zillow housing data are estimates of housing value (known as Zestimates). This hedonic approach is suggested to be less influenced by a change in the mix of property types sold or timing of sale (Dorsey et al. 2010). Since the housing data are based on value estimates (predicted sale values) rather than actual sales, there is some component of error inherent in the estimates. Zillow?s own research suggests that the error for each property is small (median error is approximately 10 percent) and estimated value is equally as likely to be overestimated as it is to be underestimated. When aggregated, these data assume only a small bias.

In addition to an estimation approach that is different from other house price indices, the sample of properties utilized to construct the national level Zillow Home Value Index (ZHVI) is broader than most alternative indices (Case-Shiller in particular). Currently, the national ZHVI covers 49 states $^{5}$ and among those states, a majority of counties are covered in calculating the national index. A number of counties are removed in the individual government level, publicly

\footnotetext{
${ }^{5}$ South Dakota is excluded.
} 
available data for quality control purposes. ${ }^{6}$ Figure 1 displays the publicly available ZHVI coverage at the county level in map form. Counties in light grey indicate an individual, county-level ZHVI is calculated for said county in at least one year in the data and counties in dark grey indicate a ZHVI is successfully matched to the Census Bureau Annual Survey of State and Local Government Finances for all years of the analysis. The spatial distribution of the data indicates an urban bias. The mean county population (median county population in parentheses) from the 2010 Census is approximately $96,000(25,841)$ residents. Of the counties covered by the Zillow data, the mean population is $230,065(94,367)$ and among the matched data the mean population is $257,733(119,290)$. This study also utilizes house price data from Zillow at the city and/or town level. These data demonstrate a similar urban bias. The mean census place population (median census place population in parentheses) from the 2010 Census is approximately 11,500 $(1,250)$ residents. Of the cities and towns covered by the Zillow data, the mean population is $21,606(5,888)$ and among the matched data the mean population is $56,633(21,514)$. Even with the urban bias, the small area aggregation of the Zillow data allows for the influence on property tax revenue of changes in local real estate prices to be assessed. Using OFHEO/FHFA data, Lutz (2008) is only able to analyze the change in state-level or MSA-level house price data on local level property tax revenue. This higher level of housing data aggregation can mask changes in local property markets and distort the results of the analysis. Of the literature examined above, only Doerner and Ihlanfeldt (2011) and Vlaicu and Whalley (2011) utilize house price data from the same geographic location as the local government budgetary data. ${ }^{7}$

Figure 2 compares the ZHVI to three popular house price indices from the third quarter of 1997 to the fourth quarter of 2012. It can easily be seen that the four indices are quite similar over time. Indeed, the pairwise correlation between the ZHVI and the three other indices is quite high (0.961 for Case-Shiller, 0.999 for OFHEO/FHFA, and 0.98 for CoreLogic). All three comparison indices are repeat sales indices. CoreLogic and S\&P/(Case and Shiller 1989) ${ }^{8}$ are the most similar in both construction (weighted repeat sales) and the inclusion of properties in the index. Both include only single family homes and do not include new construction. ${ }^{9}$ The large differences between CoreLogic and S\&P/Case-Shiller and the OFHEO/FHFA index around the peak of the market is the types of properties included; the OFHEO/FHFA index only includes conforming mortgages (Calhoun 1996). The maximum mortgage value was $\$ 207,000$ in 1996 and rose to $\$ 417,000$ in 2008. Similar to CoreLogic and S\&P/Case-Shiller, this index does not include new residential construction (the repeat sales method requires at least two sales of the property, thus excluding new construction). Additionally, the weighting method differs between the indices. As mentioned above, the ZHVI is a hedonic approach, includes new construction, and includes both single family homes and condominiums/co-ops. The differences in calculation account for the differences in figure 2 .

\footnotetext{
${ }^{6}$ See https://www.zillow.com/research/zhvi-methodology-6032/ for more information on the final quality control process utilized by Zillow.

${ }^{7}$ Ihlanfeldt (2011) also utilizes matched data; however, he examines changes in the property tax base directly rather than through house prices.

${ }^{8}$ The rights to the Case-Shiller index were acquired by CoreLogic in April 2013.

${ }^{9}$ CoreLogic also report single family minus distressed, single family attached and single family detached. These indices are not displayed.
} 
Figure 1: Zillow ${ }^{\circledR}$ House Value Index County Coverage

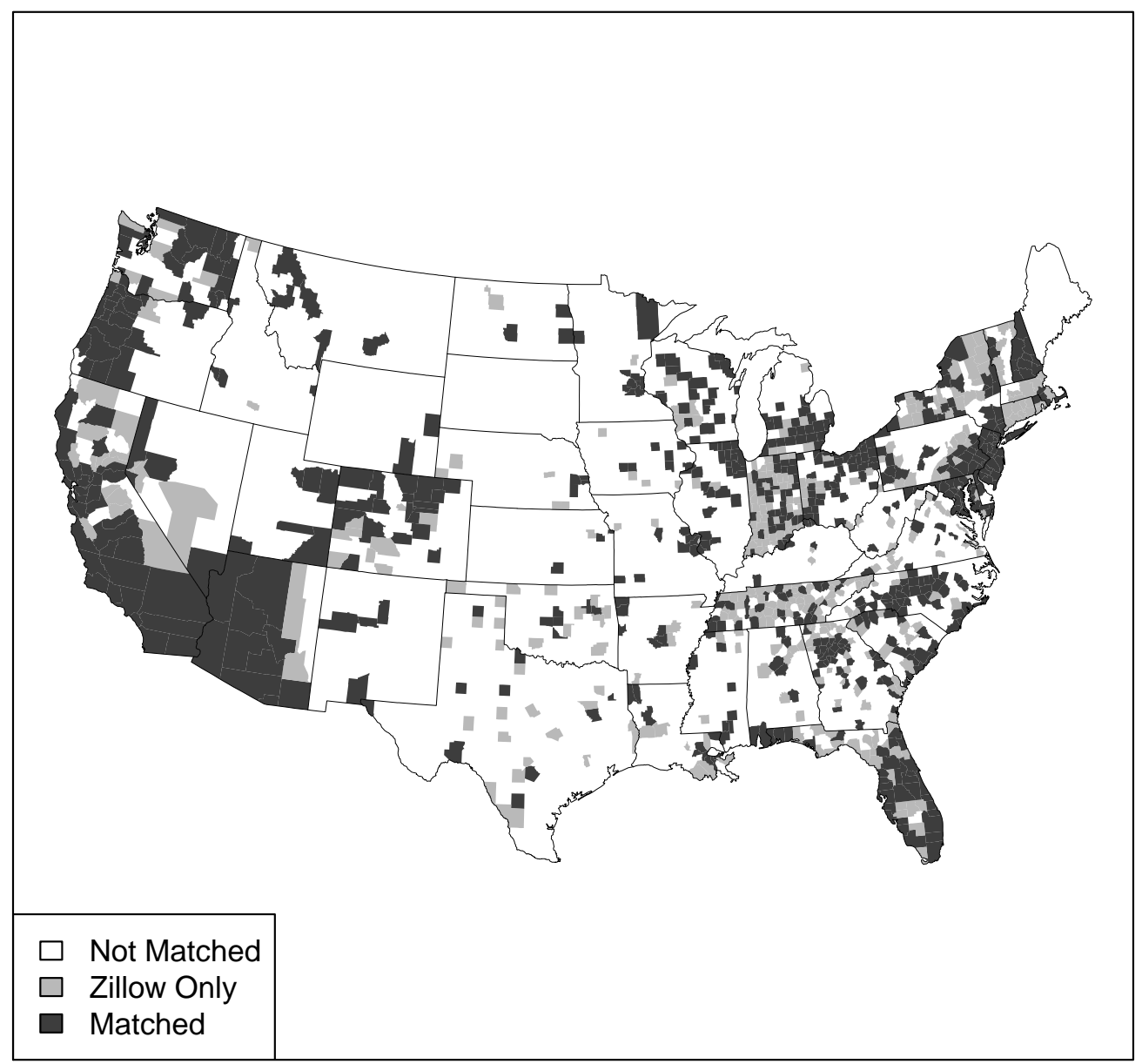

\section{Small Area Analysis}

The small area analysis presented in this paper utilizes panel data on cities, towns, and counties that derive revenue from the property tax. Unlike Lutz (2008) and Lutz, Molloy, and Shan (2011), this analysis utilizes data on both sides of the estimating equation from the same level of aggregation. This approach allows local changes in house values to influence local property tax collections. This approach is expected to yield more accurate and policy-relevant conclusions. However, it does sacrifice some statistical power by a significant reduction in number of observations available for analysis. The time-series for this analysis runs from 1998 to 2012 and is necessitated by the availability of city and county level data from Zillow. Other house price indices mentioned above are available for a longer time-series, but the smallest level of geographic aggregation is the metropolitan level. 
Figure 2: Comparison of U.S. House Price Indices

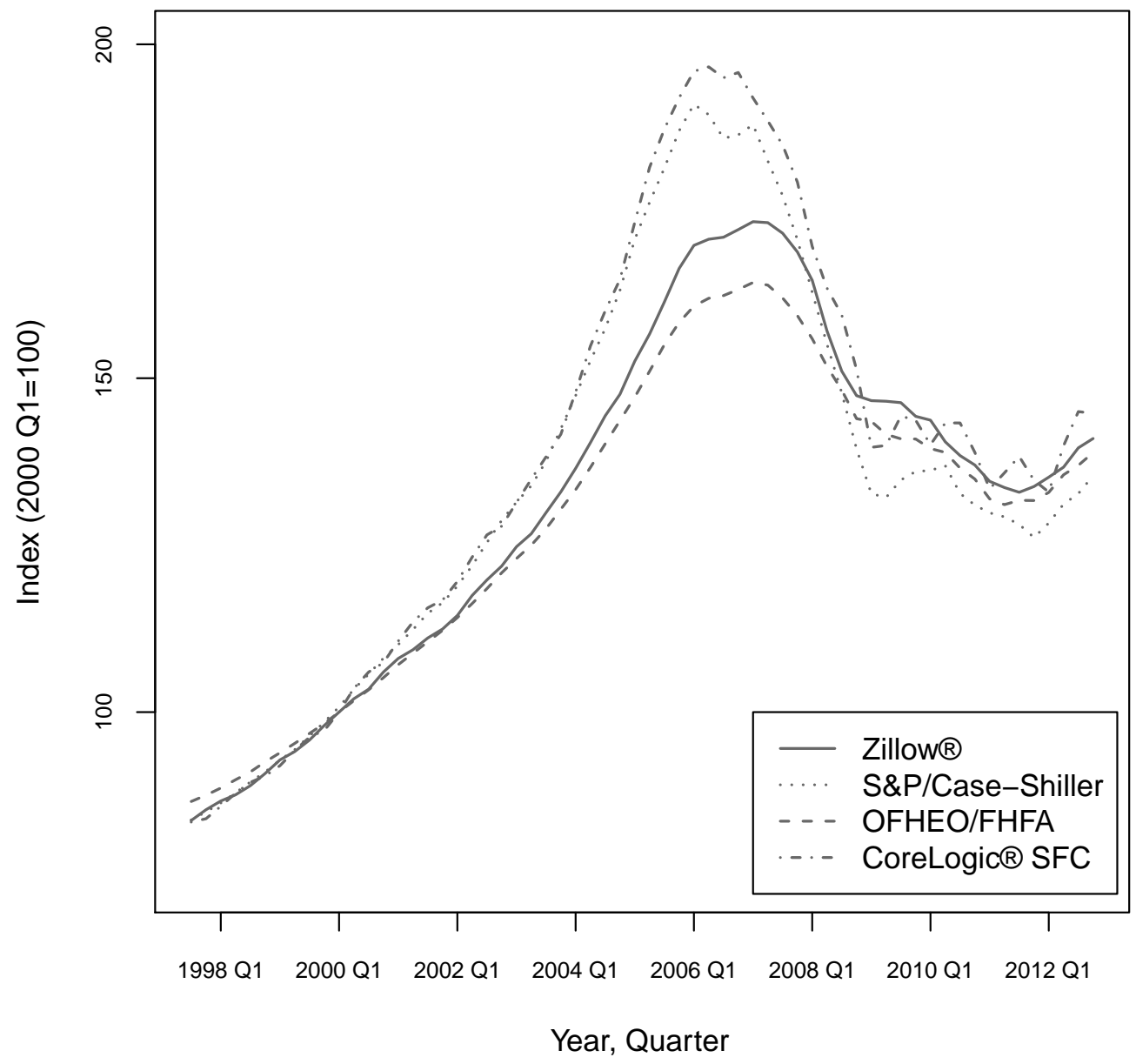

As mentioned previously, the property tax data for this analysis is extracted from the $A n$ nual Survey of State and Local Government Finances and the house value data are sourced from Zillow. Zillow provides various levels of aggregation of their data from the zip code level to the national level. For this analysis, the data from counties and cities are utilized. Property tax data are matched to these data to provide the complete dataset (See Figure 1). Regressions are run separately for each level of aggregation. 
Following Lutz (2008), the estimating equation for this analysis is

$$
\begin{aligned}
\Delta \ln R_{i, t}=\alpha & +\sum_{j=1}^{4} \beta_{i} \Delta \ln V_{i, t-j} \\
& +\sum_{j=1}^{4} \beta_{\text {small }, i} \Delta \ln V_{i, t-j} *(\text { small }) \\
& +\sum_{j=1}^{4} \beta_{\text {large }, i} \Delta \ln V_{i, t-j} *(\text { large }) \\
& +\sum_{j=1}^{4} \beta_{\text {decrease }, i} \Delta \ln V_{i, t-j} *(\text { decrease }) \\
& +\delta \Delta X+\epsilon_{i, t}
\end{aligned}
$$

where $R$ is total property tax revenue in jurisdiction $i$ in time $t, V_{i, t}$ is the value of aggregate housing, the Zillow median house value, for jurisdiction $i$ in time $t$, and $X$ is a vector of control variables. This model is interacted to allow for multiple responses to take place given different changes in aggregate house values: small is an indicator variable equal to one if the change in house value $\left.\left(\Delta \ln V_{i, t-j}\right)\right)$ is non-negative and no larger than the 25th percentile, large is an indicator variable equal to one if the change in house value is larger than the 75th percentile, and decrease is an indicator variable equal to one if the change in house value is negative. For the county sample, the mean decrease in housing prices is -5.6 percent, the mean small increase is 0.9 percent and the mean large increase is 8.9 percent. For the city and town sample, the mean decrease in housing prices is -6.1 percent, the mean small increase is 1.1 percent and the mean large increase is 9.4 percent. The model is fully differenced to eliminate any time invariant effects (i.e. locational fixed effects) that may influence property tax collections. Failing to do so would likely introduce an omitted variable bias. A byproduct of this procedure is to lessen any potential bias that results from serial autocorrelation. As discussed more fully before, the control variables contained in the vector $X$ are lagged by one year in an attempt to break any correlation with the error term that may bias the coefficients, ?. The standard errors are clustered on the county for both the city-level and county-level analyses. This model is a form of a distributed lag model and can be interpreted as follows: individual point estimates are the effect of a temporary change in right hand side variable, cumulative point estimates are the effect of a permanent change in the right hand side variable on the dependent variable. Lutz (2008), cumulative point estimates are displayed in the tables and figures. With the interaction terms, the cumulative point estimate is the sum of the primary effect plus the sum of the interacted effect. For instance, the cumulative point estimate for the effect of a decrease in house prices lagged 3 years is $\beta_{1}+\beta_{2}+\beta_{3}+\beta_{\text {decrease, } 1}+\beta_{\text {decrease }, 2}+\beta_{\text {decrease }, 3}$.

This analysis presents four primary models. The first is the estimation of equation 3 on the complete sample of cities and counties with the vector $X$ containing four lagged differences of population and per capita personal income data aggregated to the county level. The second model presents the same model as the first but includes only those states that require mandatory reassessment of properties (Anderson 2006). By requiring that local governments reassess property on an annual basis, changes in house prices may be incorporated into assessed values at a faster pace than they otherwise would. If this is the case, the mechanical process from equation 2 will occur faster but may be policy changes. Similar to annual assessment requirements, truth-in-taxation or 
full disclosure rules ${ }^{10}$ may alter the speed or intensity at which any policy offset may occur. The requirement to hold public meetings about any potential increase in revenue may induce local policymakers to offset increases in house prices by lowering the millage rate. The third model is the same as the first but is only for states that have truth-in-taxation requirements for their cities or counties. The final model presents equation 3 with the vector $X$ containing Census region-year fixed effects in an attempt to eliminate any unobserved regional heterogeneity that may bias the results.

The estimation of equation 3 is presented in table 1. Cumulative point estimates are reported as well as a 95 percent confidence interval. To aid in interpretation, these results are also presented graphically in figure 3 with counties presented in panel (a) and cities in panel (b). As mentioned above, there are two questions to be answered by this analysis. The first question seeks to ascertain the elasticity of property tax revenue with respect to housing values. As a byproduct, answering this question allows us to determine an approximation of how much of increases in housing values are offset by the actions of local policy makers. An elasticity of one indicates local policy makers engage in no offset of effective tax rates as the result of rising property values and the local government captures 100 percent of the increase. In the figure presented, an asterisk indicates rejection of the null hypothesis of elasticity equal to one. An elasticity of zero indicates that local policy makers completely offset any increases in house prices and property tax collections remain constant year over year. In the figures presented, a large shape indicates rejection of the null hypothesis of elasticity equal to zero. The second question seeks to determine the average length of time it takes for changes in housing values to be translated into assessed values and property tax revenues.

Turning first to the county sample, it is clear that a normal increase in house values (the middle 50 percent of changes), is somewhat atypical from the other changes in house values. In the initial three years after a change in house values, we are unable to distinguish the elasticity from zero indicating that we cannot rule out that local policy makers completely offset an increase in house prices. We are able to reject the null hypothesis that the elasticity equals one, ruling out a complete capture of the increase in value. In year 4 , the elasticity is 0.27 and is distinguishable from zero. Additionally, the null hypothesis that the elasticity equal one is rejected. These results indicate that there is an identifiable relationship between normal increases in house values and changes in property tax revenues in year four, and local policy makers do not completely capture increases in house values or completely offset them.

The influence of large increases in house values, those of larger than the 75th percentile, is rather muted. All four lags are statistically different than one allowing the rejection of the null hypothesis that counties capture 100 percent of the increase in house values. The elasticity is small and distinguishable from zero in the second and forth year. Therefore, two years after a large change in house values and again four years after a large change in value, counties capture only 15 to 20 percent of change in house values. This result makes intuitive sense, as homeowners are likely more sensitive to large changes in property tax burdens than small changes. The prospect of a large increase in property tax burdens puts significant political pressure on local policy makers to capture a smaller portion of the increase in house values than normal circumstances.

\footnotetext{
${ }^{10}$ Truth-in-taxation or full disclosure requirements are a form of tax and expenditure limitation that requires public meetings, a specific legislative vote, or both before property taxes can be raised (Mullins and Wallin 2004). This often includes when the mechanical process leads to increases in tax revenue without a policy offset.
} 
Table 1: Small Area Estimates, $X=\Delta \ln (p o p), \Delta \ln (p c y)$

\begin{tabular}{|c|c|c|c|}
\hline Change in House Price & Cumulative Point Estimate & Upper 95\% CI & Lower 95\% CI \\
\hline \multicolumn{4}{|l|}{ County Sample, $n=5,821$} \\
\hline Normal Increase, Year 1 & 0.3821 & -0.2013 & 0.9656 \\
\hline Normal Increase, Year 2 & 0.4620 & -0.0229 & 0.9470 \\
\hline Normal Increase, Year 3 & -0.1183 & -0.4540 & 0.2174 \\
\hline Normal Increase, Year 4 & 0.2722 & 0.0370 & 0.5074 \\
\hline Small Increase, Year 1 & 0.1405 & -0.5392 & 0.8202 \\
\hline Small Increase, Year 2 & -0.0025 & -0.3480 & 0.3429 \\
\hline Small Increase, Year 3 & 0.0238 & -0.4436 & 0.4912 \\
\hline Small Increase, Year 4 & 0.2261 & -0.0722 & 0.5245 \\
\hline Large Increase, Year 1 & 0.1637 & -0.0544 & 0.3817 \\
\hline Large Increase, Year 2 & 0.2046 & 0.0160 & 0.3931 \\
\hline Large Increase, Year 3 & 0.1279 & -0.0669 & 0.3228 \\
\hline Large Increase, Year 4 & 0.1588 & 0.0430 & 0.2746 \\
\hline Decrease, Year 1 & 0.0367 & -0.0988 & 0.1722 \\
\hline Decrease, Year 2 & 0.1275 & -0.0013 & 0.2562 \\
\hline Decrease, Year 3 & 0.4914 & 0.3843 & 0.5984 \\
\hline Decrease, Year 4 & 0.4128 & 0.2933 & 0.5323 \\
\hline \multicolumn{4}{|l|}{ City Sample, $n=8,449$} \\
\hline Normal Increase, Year 1 & 0.1797 & -3.4554 & 3.8149 \\
\hline Normal Increase, Year 2 & 0.5392 & -0.5764 & 1.6548 \\
\hline Normal Increase, Year 3 & -1.0208 & -4.6412 & 2.5996 \\
\hline Normal Increase, Year 4 & 0.6263 & -0.5343 & 1.7869 \\
\hline Small Increase, Year 1 & -0.0808 & -0.4812 & 0.3196 \\
\hline Small Increase, Year 2 & 0.1023 & -0.0611 & 0.2656 \\
\hline Small Increase, Year 3 & 0.2845 & 0.0191 & 0.5498 \\
\hline Small Increase, Year 4 & 0.4667 & 0.2586 & 0.6749 \\
\hline Large Increase, Year 1 & -0.1270 & -0.2838 & 0.0298 \\
\hline Large Increase, Year 2 & -0.1665 & -0.4681 & 0.1352 \\
\hline Large Increase, Year 3 & 0.0200 & -0.4645 & 0.5044 \\
\hline Large Increase, Year 4 & 0.2383 & -0.0400 & 0.5167 \\
\hline Decrease, Year 1 & 0.0067 & -0.1539 & 0.1672 \\
\hline Decrease, Year 2 & 0.2797 & 0.0620 & 0.4973 \\
\hline Decrease, Year 3 & 0.3294 & 0.1244 & 0.5345 \\
\hline Decrease, Year 4 & 0.5514 & 0.3404 & 0.7624 \\
\hline
\end{tabular}




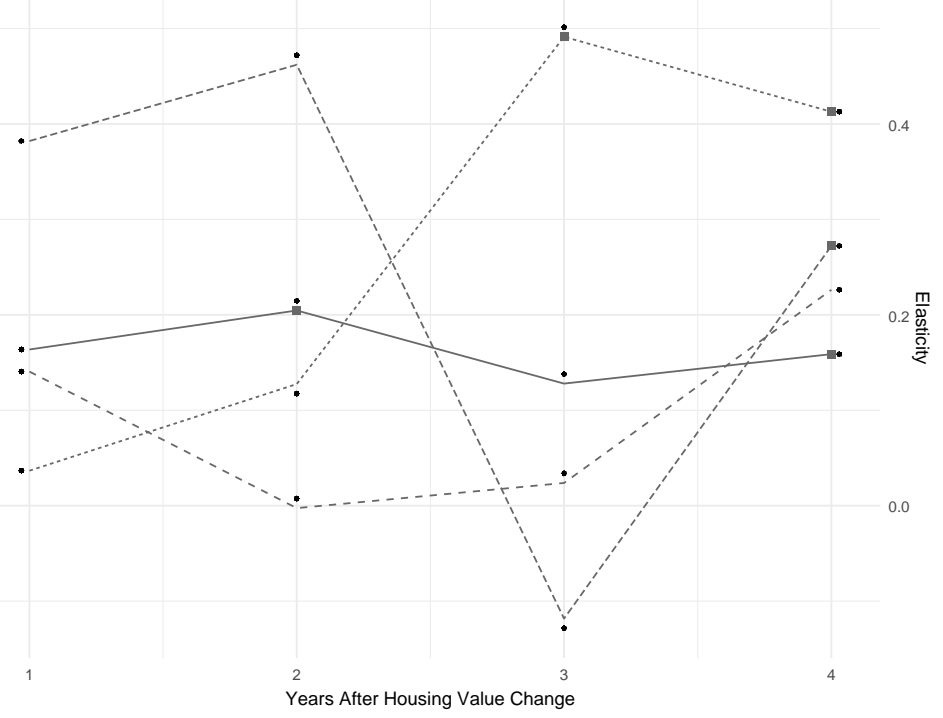

(a) County Sample

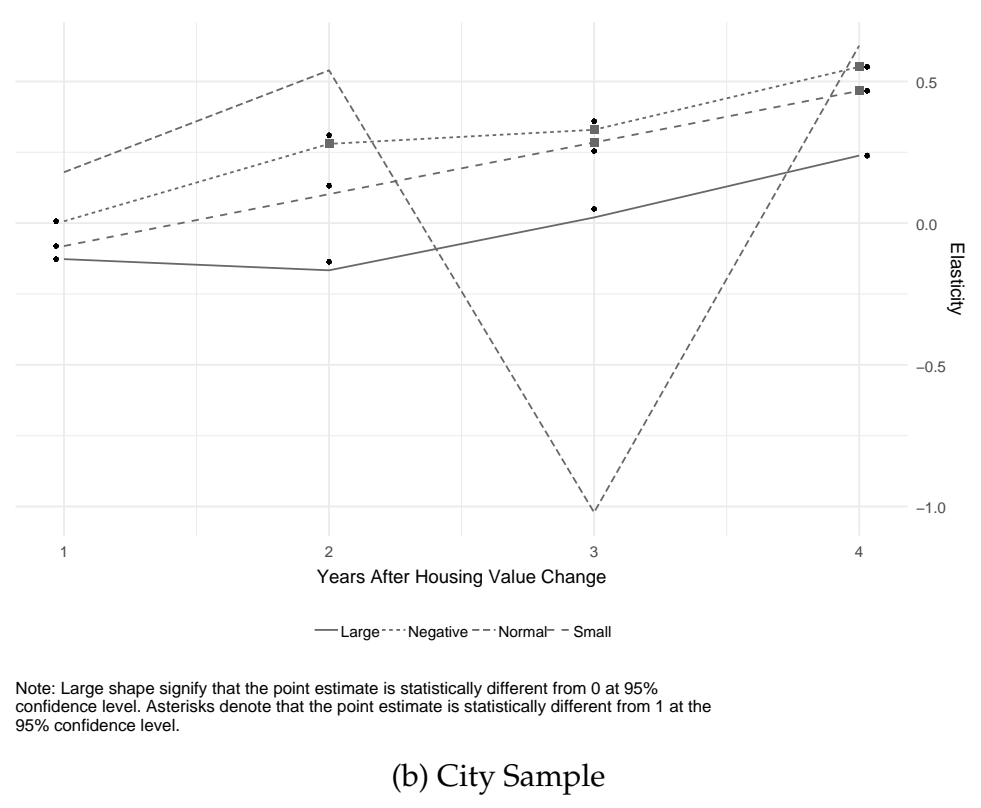

Figure 3: Small Area Estimates, $X=\Delta \ln (p o p), \Delta \ln (p c y)$ 
The influence of small increases in house values, those smaller than the 25th percentile, are generally small. All four years of the lag in changes in house prices are statistically different than one allowing the rejection of the null hypothesis that local policy makers capture all of the (small) increase in house values. However, the results are never statistically different from zero indicating that we cannot rule out that local policy makers completely offset the small increase in home values with adjustments to the effective millage rate.

The elasticity of a decrease in house values is positive and larger than the other results. For years three and four, the elasticity can be distinguished from both zero and one indicating that local policy makers decreased effective tax rates (and property tax burdens), but not by the full amount of the reduction in house values. Previous results would indicate that reductions in house prices are more than offset by increases in effective tax rates (Lutz 2008) leading to fairly stable property tax collections. During the Great Recession, local policy makers allowed property tax collections to decline, but not to the extent of house values declines. These results are particularly relevant since the time period of the analysis saw a large percentage of house value decreases, many more instances than previous analyses. ${ }^{11}$

The results for normal changes in values for the city sample are imprecise. We are unable to reject the null hypothesis that the elasticity of property tax revenue is zero or one. We are able to reject the null hypothesis that the elasticity is equal to one for all years for large increases; however, we fail to reject the null hypothesis that the elasticity is zero. These results indicate that for large changes in house prices we can eliminate the possibility for a 100 percent capture of the increase as property tax revenues, but we cannot eliminate those increases are 100 percent offset with changes to the effective millage rate. Small increases in housing value are associated with increases in property tax revenue and statistically different from both zero and one in years three and four. This result suggests that after three years, cities capture 38 percent of the (small) increase in housing value on average. Similar to the county sample, declines in house values lead to reductions in property tax revenue and the effect is reasonably quick. Starting two years after a decline, both null hypotheses (elasticity equal to zero or one) can be rejected and the average elasticity for years two through four is 0.387 . This would suggest that a decline in house values is associated with only roughly 40 percent as much of a decline in property tax revenue.

Table 2 and figure 4 display the results from equation 3 estimated on states with mandatory annual reassessment cycles. Panel (a) displays the results for counties and panel (b) displays the results for cities. Overall across the two sample, the results are similar to the full estimation; however, the elasticities are smaller for normal increases. It is important to note that while the elasticities are smaller, the results for declines in house values occur one year faster for both cities and counties. This suggests mandatory annual reassessment hastens the pace of incorporation of decreases in home values. As with the full sample, a decline in house values leads to a disproportional reduction in property tax revenue. Between the county and city sample, the elasticity is between 0.4 and 0.5 on average.

Table 3 and figure 5 display the results from equation 3 estimated on states with truth-intaxation requirements. Panel (a) displays the results for counties and panel (b) displays the results for cities. Consistent with the assumption that truth-in-taxation requirements may mute the policy offset, the elasticities found in table 3 are somewhat smaller than those found in table 1. It is

\footnotetext{
${ }^{11}$ Lutz, Molloy, and Shan (2011) suggests this is a potential problem with the results found in Lutz (2008) and their current analysis. The lagged release schedule of data pertaining the housing crisis has made examining the influence of declines in house prices difficult.
} 
Table 2: Small Area Estimates, States that Require Mandatory Reassessment, $X=$ $\Delta \ln (p o p), \Delta \ln (p c y)$

\begin{tabular}{|c|c|c|c|}
\hline Change in House Price & Cumulative Point Estimate & Upper 95\% CI & Lower 95\% CI \\
\hline \multicolumn{4}{|l|}{ County Sample, $n=2,504$} \\
\hline Normal Increase, Year 1 & -0.0261 & -0.5072 & 0.4550 \\
\hline Normal Increase, Year 2 & -0.0018 & -0.4435 & 0.4399 \\
\hline Normal Increase, Year 3 & 0.5380 & -0.1984 & 1.2745 \\
\hline Normal Increase, Year 4 & 0.1796 & -0.0885 & 0.4478 \\
\hline Small Increase, Year 1 & -0.3035 & -1.0918 & 0.4849 \\
\hline Small Increase, Year 2 & 0.3251 & -0.0070 & 0.6572 \\
\hline Small Increase, Year 3 & 0.3204 & -0.0158 & 0.6565 \\
\hline Small Increase, Year 4 & 0.3778 & 0.1437 & 0.6118 \\
\hline Large Increase, Year 1 & 0.0036 & -0.2011 & 0.2083 \\
\hline Large Increase, Year 2 & 0.2097 & -0.0015 & 0.4209 \\
\hline Large Increase, Year 3 & 0.1451 & -0.0160 & 0.3063 \\
\hline Large Increase, Year 4 & 0.2364 & 0.1270 & 0.3458 \\
\hline Decrease, Year 1 & 0.0562 & -0.0354 & 0.1477 \\
\hline Decrease, Year 2 & 0.3568 & 0.2388 & 0.4748 \\
\hline Decrease, Year 3 & 0.5937 & 0.4928 & 0.6947 \\
\hline \multirow[t]{2}{*}{ Decrease, Year 4} & 0.6244 & 0.5073 & 0.7415 \\
\hline & 0.5250 & & \\
\hline \multicolumn{4}{|l|}{ City Sample, $n=5,097$} \\
\hline Normal Increase, Year 1 & -0.3464 & -6.0958 & 5.4029 \\
\hline Normal Increase, Year 2 & 0.1068 & -1.1995 & 1.4131 \\
\hline Normal Increase, Year 3 & -2.8993 & -8.3345 & 2.5359 \\
\hline Normal Increase, Year 4 & 0.3510 & -0.8313 & 1.5334 \\
\hline Small Increase, Year 1 & 0.0229 & -0.5714 & 0.6173 \\
\hline Small Increase, Year 2 & 0.1072 & -0.1327 & 0.3471 \\
\hline Small Increase, Year 3 & 0.3455 & -0.0603 & 0.7513 \\
\hline Small Increase, Year 4 & 0.4615 & 0.2147 & 0.7084 \\
\hline Large Increase, Year 1 & -0.0773 & -0.3598 & 0.2052 \\
\hline Large Increase, Year 2 & -0.1232 & -0.6065 & 0.3601 \\
\hline Large Increase, Year 3 & -0.0582 & -0.8103 & 0.6939 \\
\hline Large Increase, Year 4 & 0.2872 & -0.0601 & 0.6344 \\
\hline Decrease, Year 1 & 0.0470 & -0.2362 & 0.3302 \\
\hline Decrease, Year 2 & 0.3125 & 0.0506 & 0.5744 \\
\hline Decrease, Year 3 & 0.3678 & 0.0660 & 0.6697 \\
\hline Decrease, Year 4 & 0.5791 & 0.3301 & 0.8280 \\
\hline
\end{tabular}




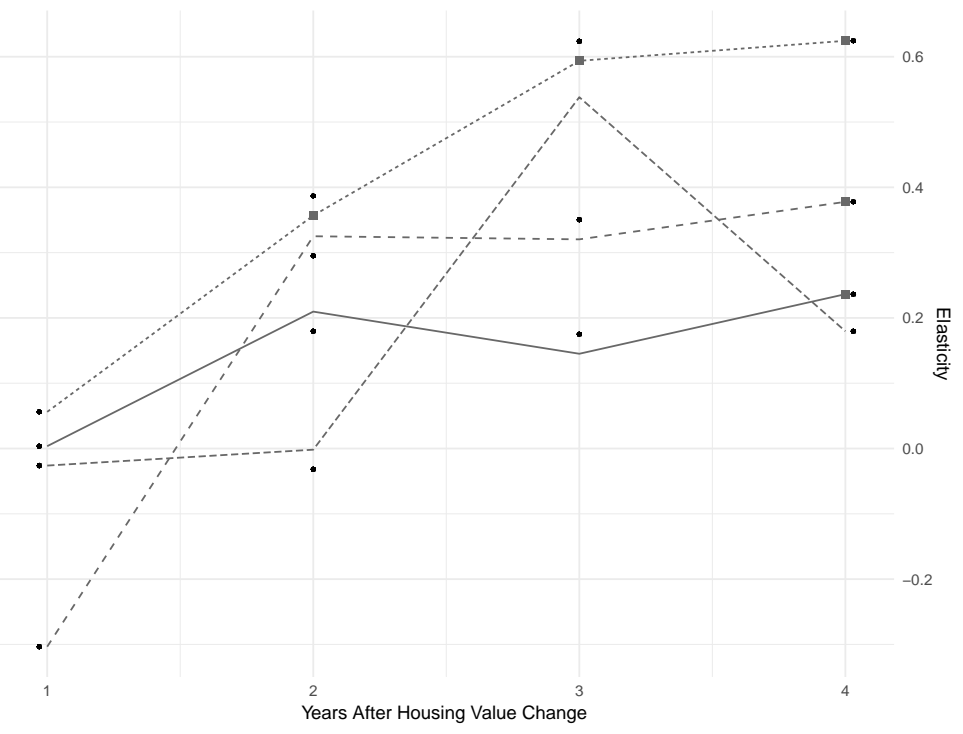

(a) County Sample

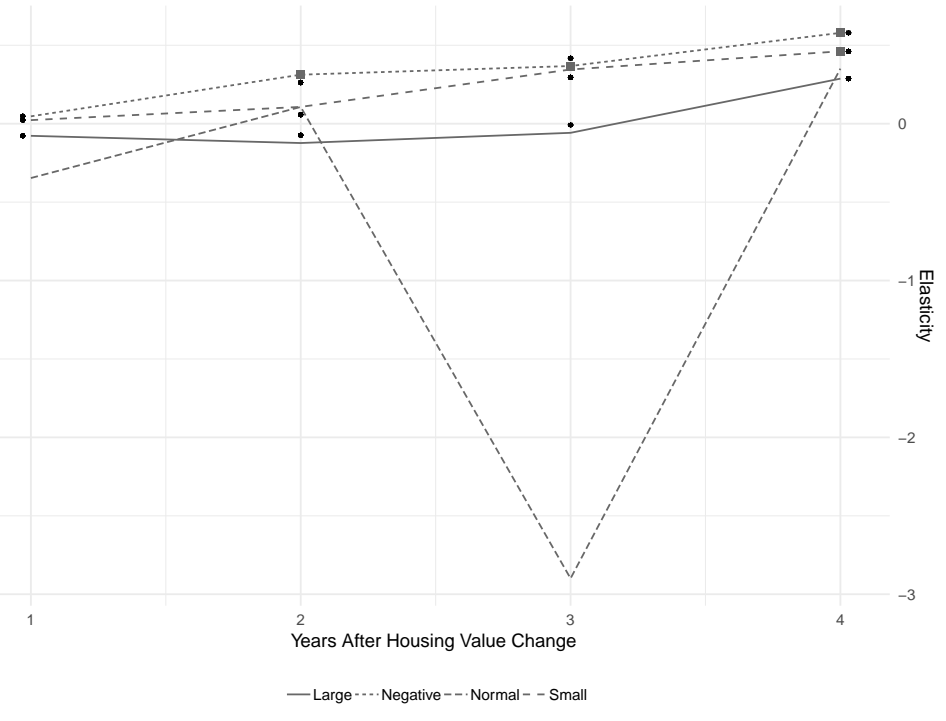

(b) City Sample

Figure 4: Small Area Estimates, States that Require Mandatory Reassessment, $X=$ $\Delta \ln (p o p), \Delta \ln (p c y)$ 
Table 3: Small Area Estimates, States with Truth-in-Taxation Laws, $X=\Delta \ln (p o p), \Delta \ln (p c y)$

\begin{tabular}{|c|c|c|c|}
\hline Change in House Price & Cumulative Point Estimate & Upper 95\% CI & Lower 95\% CI \\
\hline \multicolumn{4}{|l|}{ County Sample, $n=2,650$} \\
\hline Normal Increase, Year 1 & -0.0459 & -0.2338 & 0.1421 \\
\hline Normal Increase, Year 2 & 0.1019 & -0.1713 & 0.3751 \\
\hline Normal Increase, Year 3 & 0.1844 & -0.1733 & 0.5420 \\
\hline Normal Increase, Year 4 & 0.2329 & -0.0134 & 0.4792 \\
\hline Small Increase, Year 1 & -0.2340 & -1.1344 & 0.6664 \\
\hline Small Increase, Year 2 & 0.0939 & -0.2930 & 0.4808 \\
\hline Small Increase, Year 3 & -0.2219 & -0.8566 & 0.4127 \\
\hline Small Increase, Year 4 & 0.1615 & -0.2228 & 0.5458 \\
\hline Large Increase, Year 1 & -0.0406 & -0.2551 & 0.1739 \\
\hline Large Increase, Year 2 & -0.0417 & -0.2739 & 0.1906 \\
\hline Large Increase, Year 3 & 0.1256 & -0.0973 & 0.3485 \\
\hline Large Increase, Year 4 & 0.2829 & 0.0908 & 0.4750 \\
\hline Decrease, Year 1 & 0.0968 & 0.0038 & 0.1897 \\
\hline Decrease, Year 2 & 0.0962 & -0.0287 & 0.2210 \\
\hline Decrease, Year 3 & 0.4379 & 0.3129 & 0.5629 \\
\hline Decrease, Year 4 & 0.3930 & 0.2542 & 0.5317 \\
\hline \multicolumn{4}{|l|}{ City Sample, $n=2,469$} \\
\hline Normal Increase, Year 1 & 0.2594 & -9.8251 & 10.3439 \\
\hline Normal Increase, Year 2 & 1.9107 & -0.8026 & 4.6240 \\
\hline Normal Increase, Year 3 & -4.7143 & -14.2498 & 4.8211 \\
\hline Normal Increase, Year 4 & 1.3956 & -1.1889 & 3.9801 \\
\hline Small Increase, Year 1 & -0.1370 & -0.7317 & 0.4576 \\
\hline Small Increase, Year 2 & 0.1851 & -0.1544 & 0.5246 \\
\hline Small Increase, Year 3 & 0.3623 & -0.0702 & 0.7948 \\
\hline Small Increase, Year 4 & 0.8576 & 0.3914 & 1.3237 \\
\hline Large Increase, Year 1 & 0.0270 & -0.2556 & 0.3097 \\
\hline Large Increase, Year 2 & -0.2880 & -1.1151 & -1.1151 \\
\hline Large Increase, Year 3 & -0.2851 & -2.8032 & 2.2331 \\
\hline Large Increase, Year 4 & 0.7456 & 0.1772 & 1.3140 \\
\hline Decrease, Year 1 & -0.0293 & -0.4502 & 0.3915 \\
\hline Decrease, Year 2 & 0.0545 & -0.3987 & 0.5078 \\
\hline Decrease, Year 3 & 0.2205 & -0.1112 & 0.5522 \\
\hline Decrease, Year 4 & 0.5293 & 0.2747 & 0.7839 \\
\hline
\end{tabular}




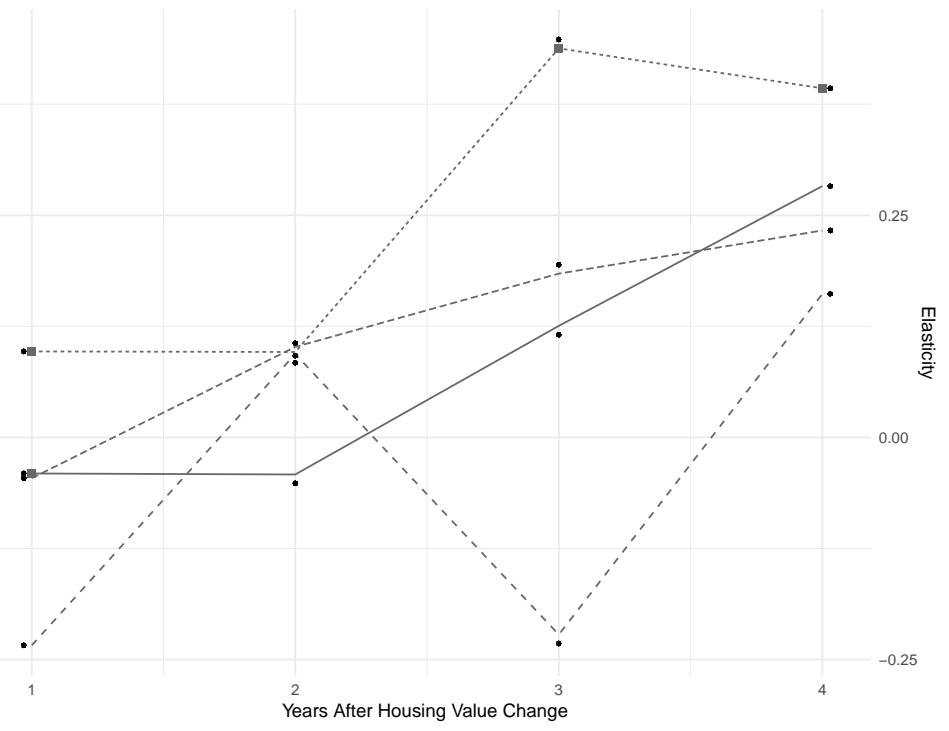

(a) County Sample

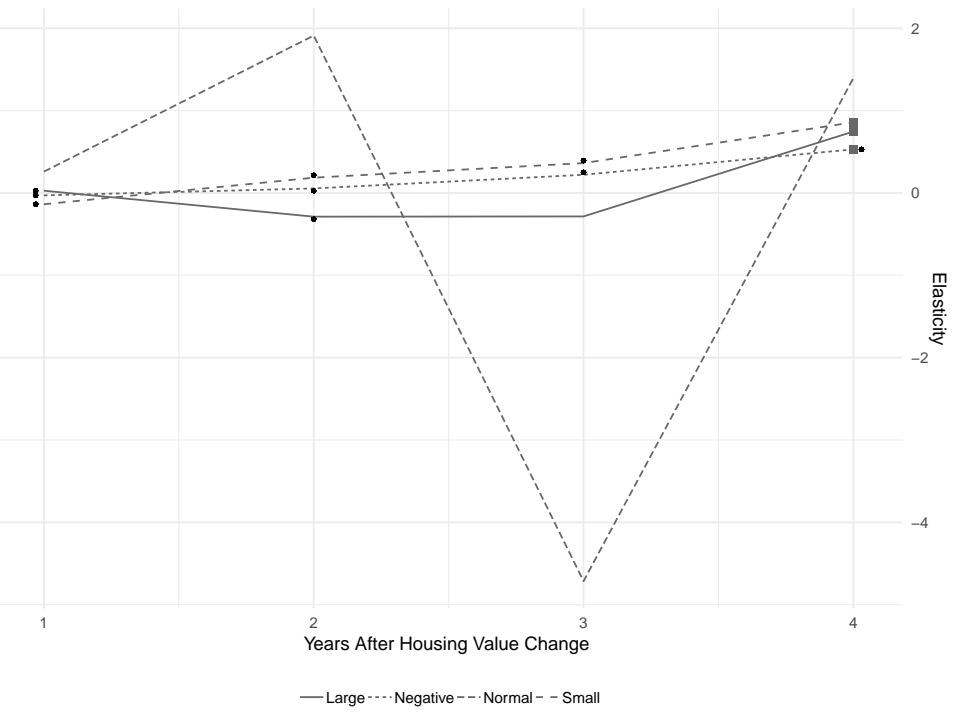

(b) City Sample

Figure 5: Small Area Estimates, States with Truth-in-Taxation Laws, $X=\Delta \ln (p o p), \Delta \ln (p c y)$ 
important to note that the timing is largely unchanged from the full results; however, there are some instances where the timing has been elongated, occurring in year 4 rather than year 3 . This result is particularly pronounced for large changes in house value. This result is also consistent with the assumption that truth-in-taxation laws may slow down the process of translating changes in house values into property tax revenue.

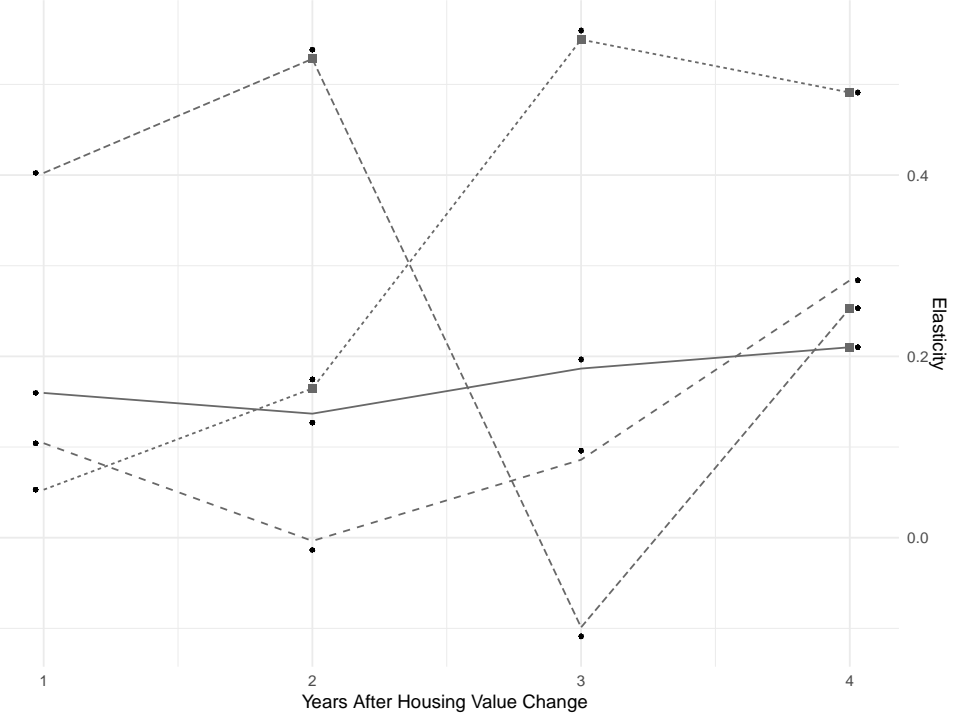

(a) County Sample

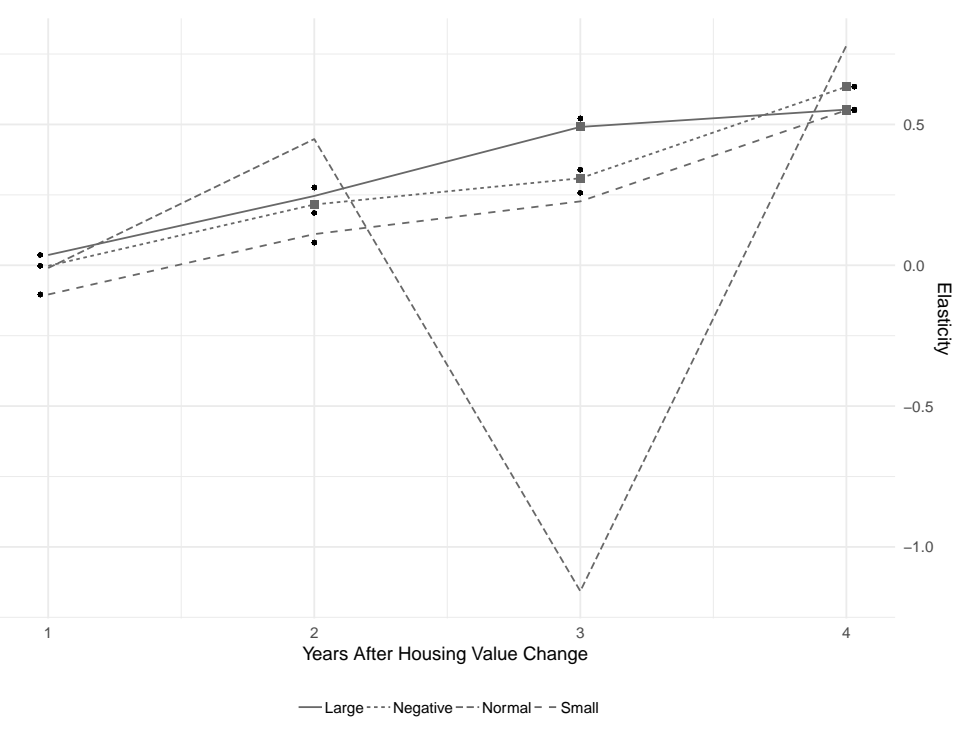

(b) City Sample

Figure 6: Small Area Estimates, $X=$ Census Region-Year Fixed Effects

The final model, replacing $X$ with a series of Census region-year fixed effects, is shown in table 4 and figures 6. Panel (a) displays the results for counties and panel (b) displays the results for cities. These fixed effects control for any region specific, time varying influences such as regional economic effects. Qualitatively, these results are similar to the full sample results outlined above; however, the estimated elasticities are larger. In both the city and county sample, we are able 
Table 4: Small Area Estimates, $X=$ Census Region-Year Fixed Effects

\begin{tabular}{|c|c|c|c|}
\hline Change in House Price & Cumulative Point Estimate & Upper 95\% CI & Lower $95 \%$ CI \\
\hline \multicolumn{4}{|l|}{ County Sample, $n=5,821$} \\
\hline Normal Increase, Year 1 & 0.4023 & -0.1532 & 0.9578 \\
\hline Normal Increase, Year 2 & 0.5281 & 0.0581 & 0.9982 \\
\hline Normal Increase, Year 3 & -0.0989 & -0.4205 & 0.2227 \\
\hline Normal Increase, Year 4 & 0.2532 & 0.0053 & 0.5010 \\
\hline Small Increase, Year 1 & 0.1042 & -0.5375 & 0.7459 \\
\hline Small Increase, Year 2 & -0.0036 & -0.3648 & 0.3576 \\
\hline Small Increase, Year 3 & 0.0860 & -0.3725 & 0.5445 \\
\hline Small Increase, Year 4 & 0.2839 & -0.0204 & 0.5881 \\
\hline Large Increase, Year 1 & 0.1597 & -0.0730 & 0.3923 \\
\hline Large Increase, Year 2 & 0.1368 & -0.0612 & 0.3348 \\
\hline Large Increase, Year 3 & 0.1866 & -0.0082 & 0.3814 \\
\hline Large Increase, Year 4 & 0.2101 & 0.0842 & 0.3359 \\
\hline Decrease, Year 1 & 0.0529 & -0.1004 & 0.2063 \\
\hline Decrease, Year 2 & 0.1646 & 0.0265 & 0.3027 \\
\hline Decrease, Year 3 & 0.5494 & 0.4385 & 0.6603 \\
\hline Decrease, Year 4 & 0.4910 & 0.3633 & 0.6187 \\
\hline \multicolumn{4}{|l|}{ City Sample, $n=8,449$} \\
\hline Normal Increase, Year 1 & -0.0097 & -3.6320 & 3.6125 \\
\hline Normal Increase, Year 2 & 0.4480 & -0.6667 & 1.5628 \\
\hline Normal Increase, Year 3 & -1.1571 & -4.7342 & 2.4199 \\
\hline Normal Increase, Year 4 & 0.7800 & -0.5434 & 2.1033 \\
\hline Small Increase, Year 1 & -0.1038 & -0.5062 & 0.2986 \\
\hline Small Increase, Year 2 & 0.1106 & -0.1448 & 0.3660 \\
\hline Small Increase, Year 3 & 0.2269 & -0.0684 & 0.5222 \\
\hline Small Increase, Year 4 & 0.5505 & 0.2330 & 0.8679 \\
\hline Large Increase, Year 1 & 0.0365 & -0.4214 & 0.4944 \\
\hline Large Increase, Year 2 & 0.2461 & -0.2522 & 0.7443 \\
\hline Large Increase, Year 3 & 0.4912 & 0.1497 & 0.8328 \\
\hline Large Increase, Year 4 & 0.5526 & 0.0511 & 1.0541 \\
\hline Decrease, Year 1 & -0.0022 & -0.1829 & 0.1785 \\
\hline Decrease, Year 2 & 0.2157 & 0.0321 & 0.3993 \\
\hline Decrease, Year 3 & 0.3089 & 0.1280 & 0.4899 \\
\hline Decrease, Year 4 & 0.6340 & 0.4369 & 0.8310 \\
\hline
\end{tabular}


to reject the null hypothesis that the estimate coefficient is zero or one for large increases and decreases. This occurs after two years lag for decreases and three (county) or four (city) years lag for large increases. The elasticity for large increases is 0.21 for counties and, on average, 0.52 for cities. This latter elasticity indicates that cities capture approximately 50 percent of the increase in housing value for large increases. The elasticity for decreases in housing value is in keeping with previous results at 0.39 for cities and 0.40 for counties. This would suggest that a decline in house values is associated with only roughly 40 percent as much of a decline in property tax revenue.

\section{Discussion \& Conclusion}

This analysis examines the influence of the house value boom and bust on property tax collection of U.S. counties and cities. The estimates provided are from small area matching, a unique approach in multi-state analyses. As such, changes in local housing markets are accounting for changes in local government property tax collections at the same geographic unit. Some previous analyses have examined this issue using state-level or MSA-level housing data to examine changes in property tax revenues for individual local government units. Even relative to matched analyses in the literature, this analysis utilizes a more recent time series of housing data allowing for the entire housing boom and bust to be examined.

This analysis examines two primary questions. What is the elasticity of property tax revenue with respect to changes in house values? Also, what is the timing of the incorporation of housing values into property tax revenues? The results presented here suggest that regardless of the type of change in house values, local governments do not capture 100 percent of the increase (or decrease) in values. Instead, they capture an increment of this increase after a three- to four-year lag on average. Additionally, the timing of the capture can be altered by state-level laws. Rules requiring annual reassessment can speed up the rate of capture while truth-in-taxation laws can slow it down. It is important to note that for many changes in values, it is not possible to rule out the possibility that local policy makers offset 100 percent of the increase in housing values by adjusting effective property tax rates. If this is the case, as house values increase, local policy makers adjust effective property tax rates downward to keep property tax revenue constant, consistent with the residual view of the property tax citepnetzer1964. This is particularly true for municipalities and towns. This result is somewhat at odds with recent research by Ihlanfeldt and Willardsen (2014) who find the millage rate offset is not strong and varies in proportion to the monopoly power of local governments. However, the results are supportive of the findings of Ross and Yan (2013).

The inability to rule out that local policy makers completely offset positive changes in housing value via changes in effective millage rates suggests a political narrative. The growing anti-tax sentiment over the study time period, coupled with the large changes in house values likely lead to significant political pressure on local policy makers to keep property tax burdens low. Indeed, there is evidence that in states with truth-in-taxation requirements, local policy makers took one year longer to incorporate large changes in home values to property tax revenues. The increased visibility of the required full disclosure proceedings is likely to result in the kind of political pressure that could keep local governments from capturing any of the potential increase in revenue as the result of changes in housing value. Actual political pressure need not be applied; the fear of political consequences from an increase in property tax revenue may be enough to result in the outcome observed here. The results presented here appear to corroborate the findings of Cornia 
and Walters (2006) that truth-in-taxation requirements can blunt the impact of rapidly appreciating houses on individual tax burdens.

The property tax revenue elasticity with respect to declining house values is an interesting case that calls for further discussion. The results presented here suggest that during the housing crash local policy makers allowed property tax revenues to decline. However, this decline was only a fraction of the decline in housing value. Estimates suggest the elasticity is between 0.3 and 0.4. This result implies that local policymakers offset between 60 and 70 percent of the potential decline in property tax revenue by adjusting effective millage rates upward. The speed at which the declines are incorporated into property tax revenues is much faster than increases, one to two years faster in most cases. Additionally, in those states with mandatory annual reassessment, declines were incorporated an additional year faster suggesting that state level factors can play a role when house prices decline. Most local revenues declined during the worst of the housing crisis, as did intergovernmental aid (Chernick, Langley, and Reschovsky 2011). However, many local revenues have rates that are difficult to change in response to changes in the revenue base. Local sales or income taxes are generally subject to rate caps and there are equity concerns with dramatic increases user charges and fees. While user charges and fees were undoubtedly increased over the Great Recession, the only other option for local policy makers to deal with declining revenues is the property tax. Brunori (2007) argues this is a virtue of the property tax; allowing the fiscal autonomy to deal with crises such as was experienced in the late 2000s. Rather than accepting the full decline in revenues that would result from the mechanical process, the full effect of the housing crisis was lessened somewhat by an upward adjustment in effective millage rates. It is likely the fiscal autonomy associated with the property tax helped local governments ride out the Great Recession.

Regarding future research, as new data becomes available, the entire lifecycle of the Great Recession should be examined from boom, bust and recovery. Unfortunately, since the influence of changes in house price on local government finances tends to happen with a significant lag, this may necessitate waiting a significant amount of time before we can completely examine the lifecycle of the Great Recession. Recent data would suggest a housing recovery is well underway and is likely to influence property tax collections. Given the importance of the property tax to local governments, ascertaining how the property tax was used during this period and whether or not it helped local governments recover more quickly is of some importance.

\section{References}

Alm, James, Robert D. Buschman, and David L. Sjoquist. 2011. "Rethinking Local Government Reliance on the Property Tax." Regional Science and Urban Economics 41 (4): 320-331.

Anderson, Nathan B. 2006. "Property Tax Limitations: An Interpretative Review." National Tax Journal 59 (3): 685-694.

Brunori, David. 2007. Local Tax Policy: A Federalist Perspective. 2nd ed. Washington, D.C.: Urban Institute Press.

Calhoun, Charles A. 1996. OFHEO House Price Indexes: HPI Technical Description. Tech. rep. Washington D.C.: Office of Federal Housing Enterprise Oversight.

Case, Karl E., and Robert J. Shiller. 1989. “The Efficiency of the Market for Single-Family Homes.” American Economic Review 79 (1): 125-137. 
Chernick, Howard, Adam Langley, and Andrew Reschovsky. 2011. "The impact of the great recession and the housing crisis on the financing of America's largest cities." Regional Science and Urban Economics 41 (4): 372-381.

Cornia, Gary C., and Lawrence C. Walters. 2006. "Full Disclosure: Controlling Property Tax Increases During Periods of Increasing Housing Values." National Tax Journal 59 (3): 735-749.

Doerner, William M., and Keith R. Ihlanfeldt. 2011. "House Prices and City Revenues." Regional Science and Urban Economics 41 (4): 332-342.

Dorsey, Robert E., et al. 2010. "Hendonic versus repeat-sales housing price indexes for measuring the recent boom-bust cycle." Journal of Housing Economics 19 (2): 75-93.

Gravelle, Jennifer, and Sally Wallace. 2009. "Overview of the Trends in Property Tax Base Erosion." In Erosion of the Property Tax Base: Trends, Causes, and Consequences, ed. by Nancy Y. Augustine et al. Cambridge, MA: Lincoln Institute of Land Policy.

Ihlanfeldt, Keith R. 2011. "How Do Cities and Counties Respond to Changes in Their Property Tax Base?" The Review of Regional Studies 41 (1): 27-48.

Ihlanfeldt, Keith R., and Kevin Willardsen. 2014. "The Millage Rate Offset and Property Tax Revenue Stability." Regional Science and Urban Economics 46:167-176.

Ladd, Helen F. 1991. "Property Tax Revaluation and Tax Levy Growth Revisited." Journal of Urban Economics 30 (1): 83-99.

Lincoln Institute of Land Policy. 2015. Significant Features of the Property Tax. Website.

Lutz, Byron F. 2008. "The Connection Between House Price Appreciation and Property Tax Revenues." National Tax Journal 61 (3): 555-572.

Lutz, Byron F., Raven Molloy, and Hui Shan. 2011. "The Housing Crisis and State and Local Government Tax Revenue: Five Channels." Regional Science and Urban Economics 41 (4): 306-319.

Mikesell, John L., and Cheol Liu. 2013. “Property Tax Stability: A Tax System Model of Base and Revenue Dynamics Through the Great Recession and Beyond." Public Finance E Management 13 (4): 310-334.

Mullins, Daniel R., and Bruce A. Wallin. 2004. “Tax and Expenditure Limitations: Introduction and Overview." Public Budgeting and Finance 24 (4): 2-15.

O'Sullivan, Arthur. 2001. "Limits on Local Property Taxation: The United States Experience." In Property Taxation and Local Government Finance, ed. by Wallace E. Oates. Cambridge: Lincoln Institute of Land Policy.

Ross, Justin, and Wenli Yan. 2013. "Fiscal Illusion from Property Reassessment? An Empirical Test of the Residual View." National Tax Journal 66 (1): 7-32.

Strumpf, Koleman S. 1999. "Infrequent Assessments Distort Property Taxes: Theory and Evidence." Journal of Urban Economics 46 (2): 169-199.

U.S. Census Bureau. 1987. Taxable Property Values. Vol. 2. Washington D.C.: Government Printing Office.

Vlaicu, Razvan, and Alexander Whalley. 2011. "Do Housing Bubbles Generate Fiscal Bubbles?" Public Choice 149 (1-2): 89-108. 